\title{
SiSTEM PENYIRAMAN DAN PENGUSIR HAMA OTOMATIS PADA DAUN MiNT BERBASIS MIKROKONTROLER ARDUINO UNO
}

\author{
Chusnul Chotimah $^{1)}$ dan Kurnia P.Kartika ${ }^{2)}$ \\ 1,2) Universitas Islam Balitar \\ 3) Fakultas Teknologi Informasi \\ e-mail: chusnulc71@gmail.com ${ }^{1)}$ kurnia.paranitha@gmail.com²)
}

\begin{abstract}
Kebutuhan air bagi daun mint / peppermint merupakan hal yang penting agar daun mint / peppermint tumbuh dan berkembangbiak dengan baik. Tidak hanya itu, perlindungan daun mint dari hama / serangga juga penting agar daun mint / peppermint dapat hidup dan memiliki kualitas daun yang sempurna hingga masa panen. Namun dalam masa praktiknya manusia sering lalai dalam melakukan penyiraman air dan proteksi hama pada tanaman. Untuk mengatasi masalah tersebut penyiraman daun mint / peppermint dan pengusir hama otomatis menggunakan mikrokontroler arduino uno sebagai salah satu solusinya. Penyiraman otomatis menggunakan RTC sebagai penentuan jadwal penyiraman daun mint dan sensor PIR sebagai pendeteksi adanya gerakan hama / serangga yang mendekat pada daun mint. Tujuan pembuatan alat ini adalah rancang bangun hardware, software, serta mengetahui unjuk kerja sistem penyiraman dan pengusir hama otomaatis berbasis mikrokontroler arduino uno. Pembuatan alat ini berbasis mikrokontoler arduino uno yang dikombinasikan dengan sensor RTC (Real Time Clock) dan sensor PIR (Passive Infrared). Disini arduino uno sebagai mikrokontroler utama, relay sebagai saklar pompa dan kipas, RTC sebagai pengatur jadwal penyiraman daun mint, dan sensor PIR untuk mendeteksi adanya gerakan hama / serangga yang mendekati daun mint. Berdasarkan hasil pengujian yang dilakukan, sistem penyiraman dan pengusir hama otomatis pada daun mint berbasis mikrokontroler arduino uno sudah berhasil. Semua program berjalan dengan baik sesuai dengan rencana sebelumnya. Dan untuk unjuk kerja pada daun mint secara keseluruhan telah sesuai dengan fungsi yang telah ditetapkan. Untuk penelitian selanjutnya penyiraman dan pengusir hama pada daun mint secara otomatis bisa ditambah sensor suhu untuk digunakan pada saat musim hujan. Karena pada penelitian ini alat hanya digunakan pada saat musim kemarau.
\end{abstract}

Kata Kunci : Peppermint, Arduino Uno, RTC, PIR

Abstract : Water requirements for mint / peppermint leaves are important so that mint / peppermint leaves grow and multiply well. Not only that, mint leaf protection from pests / insects is also important so that mint / peppermint leaves can live and have perfect leaf quality until harvest time. But in practice, humans are often negligent in watering and protecting pests on plants. To overcome these problems, mint / peppermint watering and automatic pest control use an arduino uno microcontroller as one solution. Automatic watering uses RTC as a schedule for minting and PIR sensors for detecting the movement of pests / insects approaching the mint leaves. The purpose of making this tool is to design hardware, software, and to find out the performance of an arduino uno microcontroller-based automatic watering pest control system. The making of this tool is based on arduino uno microcontoler combined with RTC (Real Time Clock) sensor and PIR (Passive Infrared) sensor. Here Arduino Uno as the main microcontroller, relay as a pump and fan switch, RTC as a regulator of mint leaves watering schedule, and PIR sensor to detect any movement of pests / insects that approach the mint leaves. Based on the results of the tests carried out, the automatic pest control and sprinkler system on the arduino uno microcontroller-based mint leaves has been successful. All programs run well according to the previous plan. And for the performance of mint leaves as a whole is in accordance with the established functions. For further research watering and repelling pests on mint leaves can automatically be added to the temperature sensor for use during the rainy season. Because in this study the tool is only used during the dry season.

Keywords : Peppermint, Arduino Uno, RTC, PIR

\section{PENDAhUluan}

Derkembangan IPTEK khususnya teknologi sudah demikian majunya merambah setiap bidang kehidupan. Hampir semua aktifitas manusia menggunakan teknologi modern, mulai dari dunia industri, rumah tangga bahkan pada bidang pertanian. Banyaknya penggunaan dan pemanfaatan teknologi 
yang berulang tanpa mengenal waktu dan kondisi, hal ini dapat dimanfaatkan untuk membantu mengerjakan kegiatan rutinitas manusia. Pemanfaatan teknologi modern sistem penyiram dan pengusir hama otomatis pada peppermint diharapkan dapat meningkatkan hasil produksi.

Daun mint tidak akan bisa tumbuh dan berkembang dengan baik jika penyiraman tidak sesuai kebutuhan, nantinya juga akan berpengaruh pada hasil produksi. Untuk itu perlu dilakukan penyiraman secara teratur dan terjadwal. Ketersediaan air pada masa pertumbuhan harus benar - benar diperhatikan, jika kekurangan air daun mintakan kering dan akhirnya mati. Sebaliknya jika kelebihan air, daun mintakan membusuk. Dengan selalu terpenuhinya kebutuhan akan air, maka tanaman dapat tumbuh dan berkembang biak dengan baik.

Daun mint mempunyai satu masalah dalam masa pertumbuhannya, yaitu banyaknya gangguan dari belalang. Belalang merupakan salah satu hama yang membahayakan untuk daun peppermint. Belalang menyerang daun peppermint baik yang muda maupun daun yang sudah tua dengan merusak pada bagian daun dan pucuk.Kadang-kadang pada musim kering dapat menyebabkan kerusakan parah. Daun yang dimakan menjadi berlubang-lubang dan lama kelamaan daun akan habis sehingga daun mint akan mati. Oleh karena itu perlu sistem untuk pengusir hama pada daun mint.[1]

Menjawab persoalan diatas, konsep perancangan sistem penyiraman otomatis akan menyiram tanaman pada pukul 07.00/12.00/16.00 Wib dan pengusir hama akan di deteksi dengan menggunakan sensor khusus. Sistem penyiraman otomatis pompa akan menyala pada pukul 07.00/12.00/16.00 Wib selama 8 detik, jika tidak pada pukul tersebut maka pompa akan mati. Pengusir hama otomatis, jika sensor mendeteksi adanya gerakan maka kipas akan ON/menyala selama 5 detik, sebaliknya jika sensor tidak mendeteksi adanya gerakan maka kipas OFF. Penyiraman pada daun mint harus dilakukan secara terjadwal agar mendapatkan hasil daun yang baik.

Manfaat alat penyiraman dan pengusir hama otomatis pada daun mint ini yaitu bagi peneliti dapat mengaplikasikan mata kuliah yang telah didapat, bagi universitas kampus mendapatkan referensi baru untuk merangkai alat penyiram dan pengusir hama pada daun mint secara otomatis, dan bagi pemilik kebun daun mint dapat mempermudah pemilik dalam penyiraman dan perawatan daun mint.

\section{Metode Penelitian}

Penelitian yang dilakukan menggunakan metode Research and Development (Penelitian dan Pengembangan). Sugiyono (2016:26) menjelaskan metode penelitian dan pengembangan (research and development) termasuk dalam kategori penelitian "need to do" yaitu penelitian yang hasilnya digunakan untuk membentuk pelaksanaan pekerjaan, sehingga apabila pekerjaan tersebut dibantu dengan produk yang dihasilkan dari R\&D maka akan semakin produktif, efektif dan efisien. Oleh karena itu metode penelitian dan pengembangan (R\&D) ini digunakan untuk penelitian penyusunan STD (Skripsi, Tesis, Disertasi) apabila peneliti atau mahasiswa bermaksud untuk menguji produk tertentu yang sudah ada, mengembangkan produk tertentu dan menemukan produk tertentu yang lebih efektif, baru dan original. [8]

Dari literatur dan jurnal - jurnal terdahulu yang telah dibaca serta pengamatan yang telah dilaksanakan, dan didasari adanya kebutuhan dalam pengontrolan dan perawatan tanaman peppermint, sehingga penelitian ini membahas tentang sistem penyiraman peppermint dan pengusir hamaotomatis berbasis mikrokontroler arduino uno. Alat tersebut berfungsi untuk menyiram tanaman sesuai dengan waktu yang telah ditentukan atau waktu yang telah dikehendaki pemilik tanaman.Pengusir hama otomatis berfungsi untuk melindungi peppermint agar bisa berkembangbiak dengan baik. Sehingga tujuan dari penerapan alat tersebut adalah perawatan dan mengembangbiakkan peppermint, serta pengusir hamaakan mendapatkan hasil panen yang optimal.

Dari permasalahan tersebut mendapatkan hasil bahwa alat penyiram tanaman otomatis ini berguna untuk menghasilkan daun peppermit yang baik. Alat ini menggunakan satu resistor RTC untuk penyiraman otomatis dan sensor PIR untuk pengusir hama otomatis. 


\section{A. Identifikasi Masalah}

Berdasarkan studi literature dan wawancara didapatkan permasalahan pada penyiraman dan pengusir hama yang masih manual karena memiliki beberapa kekurangan seperti penyiraman tidak sesuai jadwal dan kurangnya pengawasan pada peppermint sehingga jika dibiarkan hama belalang akan menghabiskan daun peppermint.

\section{B. Pengumpulan Data}

a. Metode Observasi

Melalui metode penelitian observasi penulis dapat memperoleh data dan informasi melalui pengamatan secara langsung pada lokasi. Dengan demikian penulis dapat melihat gejala yang terjadi sebenarnya terjadi di lapangan.

b. Wawancara

Dengan metode penelitian wawancara penulis dapat melakukan percakapan dengan pemilik daun mint untuk maksud tertentu. Dalam melakukan wawancara secara terbuka, dimaksudkan subyek mengetahui bahwa mereka sedang diwawancarai sehingga dapat diperoleh data dan informasi yang diperlukan. Wawancara dilakukan pada narasumber untuk memberikan informasi yang dibutuhkan dengan melakukan tanya jawab secara langsung. [8]

c. Studi Literatur

Studi literatur bertujuan untuk meningkatkan penguasaan data sekunder atau data tertulis yang telah ada. Data sekunder dalam penelitian ini meliputi jurnal - jurnal penelitian terdahulu dan alat -alat atau komponen pendukung yang dapat menjadi tambahan informasi untuk penelitian ini. Data sekunder diperlukan agar pengetahuan tentang konsep perancangan alat, pembahasan tentang komponen - komponen yang penulis gunakan. Berdasarkan hasil studi yang telah diperoleh pada tahap awal penelitian ini, sehingga dapat dilakukan proses pengumpulan dan pengelolahan data yang akan dijelaskan pada sub bab selanjutnya. [8]

\section{Desain Produk}

Berikut blok diagram sistem alat penyiraman tanaman peppermint dan pengusir hama secara otomatis menggunakan RTC dan sensor PIR berbasis arduino uno.

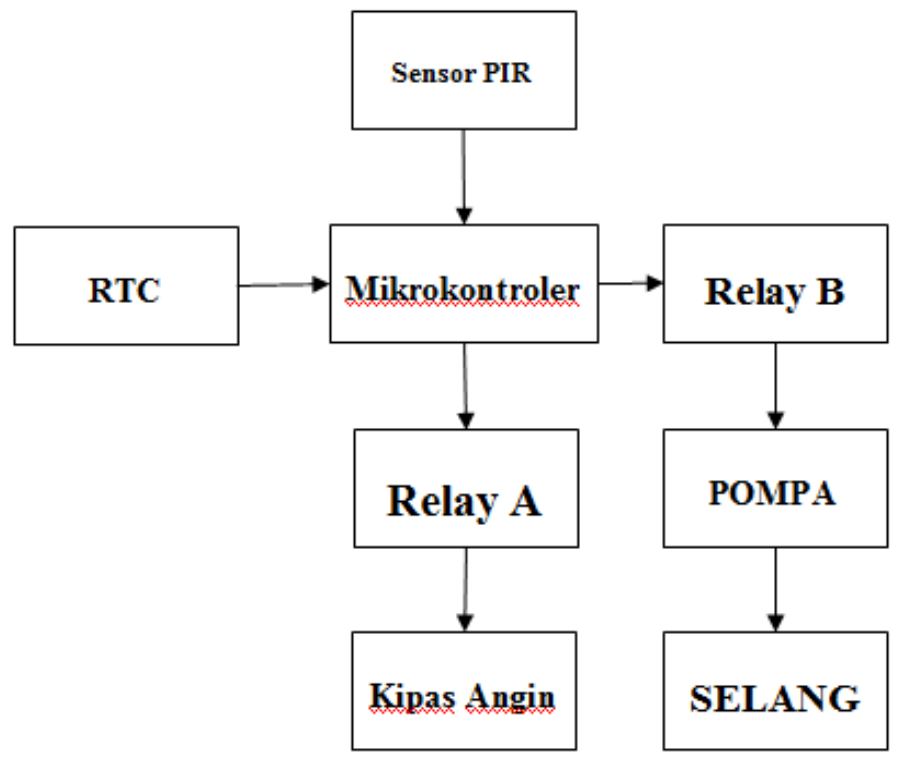

Gambar 1. Blok Diagram

Pada blok diagram prinsip kerja alat ini adalah mikrokontroler arduino uno sebagai otak dari semua alat. RTC menentukan jadwal penyiraman lalu dibaca oleh arduino, jika menunjukkan pukul 
07.00/12.00/16.00 Wib maka pompa akan menyala dan air mengalir melalui selang. Selanjutnya sensor PIR dibaca oleh arduino, jika ada pergerakan dari hama / belalang maka kipas angin akan menyala.

Tahapan dari penyiraman dan pengusir hama otomatis pada daun mint digambarkan oleh flowchart. Pada gambar 2 merupakan flowchart dari alat penyiraman dan pengusir hama otomatis pada daun mint. Flowchart tersebut menjelaskan proses kinerja alat penyiraman dan pengusir hama otomatis pada daun mint. Proses tersebut dilakukan secara bertahap, mulai dari kondisi awal sampai dengan kondisi selesai.

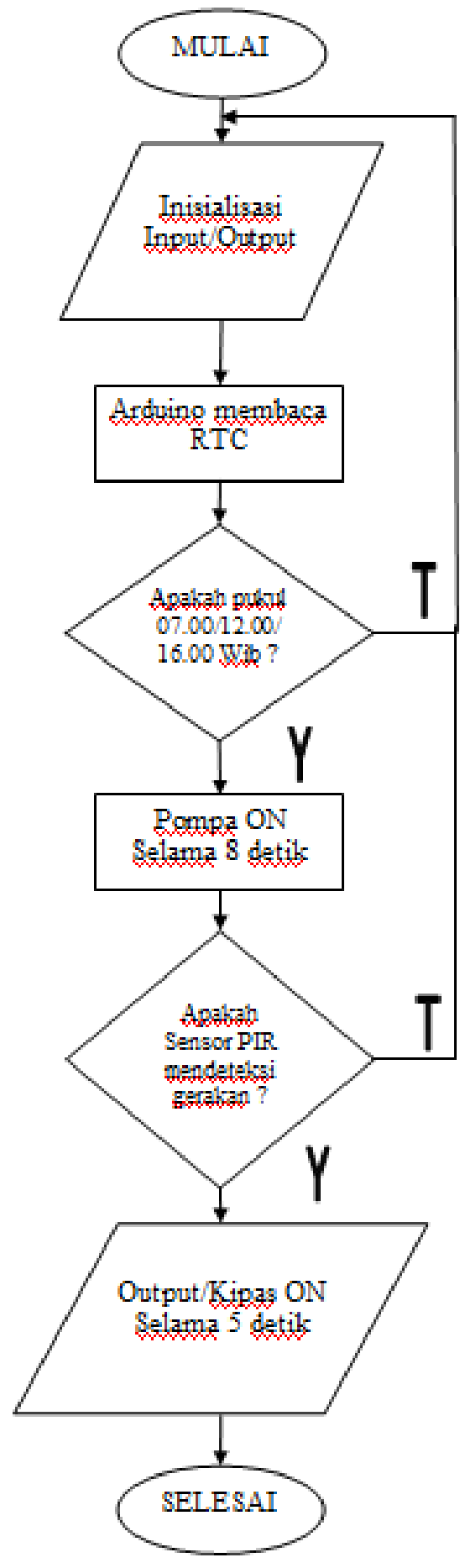

Gambar 2. Flowchart

Untuk sistem alat penyiraman dan pengusir hama otomatis pada daun mint dibutuhkan juga desain alat. Pembuatan desain alat bertujuan untuk menggambarkan alat yang berupa hardware,desain alat dapat dibuat 
untuk dijadikan sebagai acuan yang dapat mengurangi kesalahan pada perancangan alat. Gambar 3 merupakan gambar desain alat penyiraman dan pengusir hama otomatis.

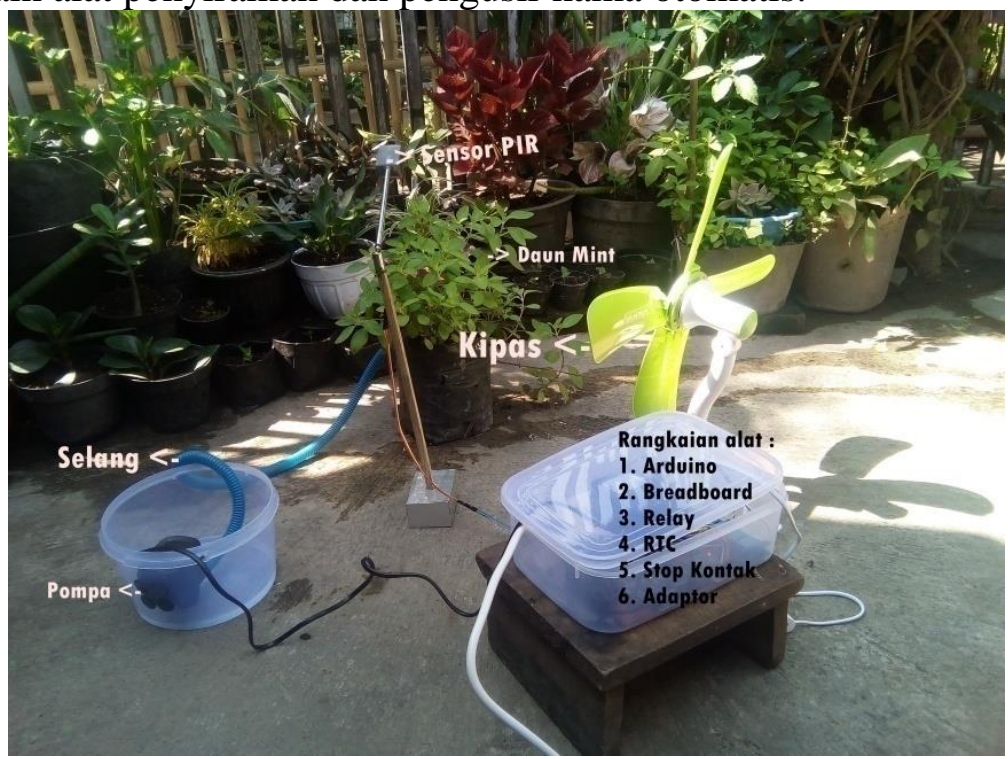

Gambar 3. Desain alat

\section{Validasi Produk}

Berdasarkan validasi yang telah dilakukan dengan beberapa aspek, dihasilkan respon yang baik oleh validator, yaitu mencapai 70\%. Sehingga alat otomatis ini dinyatakan bahwa layak untuk digunakan sebagai penghemat tenaga manusia. Ada satu catatan dari validator yaitu SOP atau petunjuk penggunaan alat otomatis ini yang masih belum tersedia.

\section{E. Uji Coba Produk}

Pengujian produk dilakukan setelah pembuatan produk berdasarkan desain yang telah diuji validasinya oleh master tehnik. Pengujian ini bertujuan untuk mengetahui apakah alat yang direalisasikan dapat bekerja sesuai dengan desain yang telah direncanakan.

Berdasarkan uji coba produk (alat dan media) kepada beberapa user dari berbagai profesi didapatkan hasil sebagai berikut :

a. Rata - rata diantara mereka belum pernah mengetahui penggunaan alat kontrol otomatis ini sebelumnya.

b. Menurut pendapat user alat ini perlu digunakan untuk membantu meringankan tenaga mereka.

c. Pemakaian alat ini mudah karena dilengkapi dengan petunjuk penggunaan.

d. Penggunaan alat ini dirasa efektif oleh para user.

\section{HASIL DAN PEMBAHASAN}

\section{A. Pengujian Alat}

Pada bab III berisi tentang hasil pengujian dan implementasi dari alat penyiraman tanaman dan pengusir hama otomatis pada daun mint. Berdasarkan waktu yang telah ditentukan dan pendeteksi gerakan serangga yang mendekat pada obyek berbasis arduino uno yang telah dibuat sesuai dengan rencana pada bab sebelumnya. Secara umum pengujian ini bertujuan untuk mengetahui apakah alat yang direalisasikan dapat bekerja sesuai dengan desain yang telah direncanakan. 


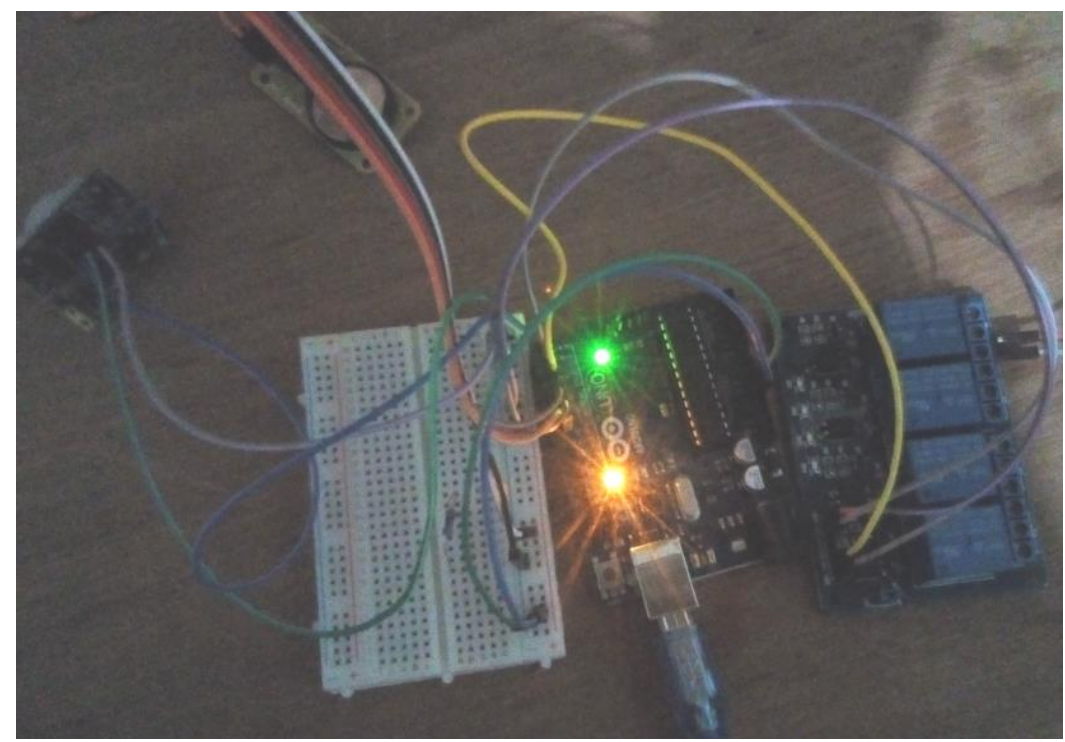

Gambar 4.1. Pengujian Arduino Uno - Relay - RTC - PIR

Alat penyiraman dan pengusir hama otomatis pada daun mint berbasis mikrokontroler arduino uno dirasa efektif oleh para user. Karena dengan alat ini petani daun mint sangat terbantu untuk menentukan jadwal penyiraman secara teratur dan juga petani daun mint tidak perlu khawatir lagi pada hama / belalang yang mengganggu atau menyerang pertumbuhan daun mint.

\section{1) Pengujian Arduino}

Pada pengujian ini didapatkan data yang sesuai dengan program yang telah diberikan pada mikrokontroler arduino uno. Hasilnya alat bekerja sesuai dengan apa yang telah kita programkan. Mikrokontroler arduino uno merupakan komponen utama pada tugas akhir ini, oleh karena itu pengujian sangat perlu dilakukan.Pada pengujian mikrokontroler terdapat beberapa error yang dapat terjadi pada mikrokontroler sebagai berikut.

1. Mikrokontroler tidak akan menyala jika ada salah satu komponen yang cacat atau rusak. Sebaiknya lakukan terlebih dahulu pengecekan terhadap rangkaian yang akan digunakan. Pastikan jika mikrokontroler benar39 benar dalam keadaan sempurna atau tidak rusak sama sekali.

2. Lampu indikator mikrokontroler redup, maka terjadi kesalahan pemasangan kutup positif dan kutup negative pada rangkaian tersebut.

3. Mikrokontroler tidak dapat berkomunikasi dengan sensor dan komponen lainnya. Hal ini dapat disebabkan oleh belum terpasangnya kabel penghubung antara sensor dan mikrokontroler. Jika sudah benar pemasangannya tekan tombol reset untuk memuat ulang program yang telah diberikan pada mikrokontroler arduino uno. Jika setelah menekan tombol reset masih terjadi error maka lakukan pemeriksaan pada program.

\section{2) Pengujian Relay}

Pengujian relay pada alat ini menggunakan cara pengujian langsung pada alat secara lengkap sehingga alat dapat bekerja secara keseluruhan.

Pada pengujian relay hal yang diuji adalah apakah modul relay sudah bekerja dengan baik atau belum ketika diberikan sinyal dari mikrokontroler berdasarkan kondisi pada RTC dan sensor PIR yang sudah ditentukan dalam program. Hasil yang didapatkan dari pengujian relay sudah sesuai dengan yang diinginkan. Berikut hal yang dapat dianalisa pada pengujian relay: 
1. Relay tidak terkoneksi dengan mikrokontroler arduino uno dengan ditandai tidak berbunyinya komparator pada relay. Pada saat pin memasukkan sinyal relay diberi masukan sinyal oleh mikrokontroler. Apabila hal ini terjadi, maka langkah - langkah yang harus dilakukan sebagai berikut :

a. Pastikan terlebih dahulu bahwa kabel tegangan positif dan negatif tidak terbalik. Jika keadaan tegangan terbalik maka relay tidak akan menyala.

b. Periksa apakah penghubung kabel antara rangkaian dengan relay dalam kondisi baik. Jika ada yang sudah tidak bekerja dengan normal segera lakukan penggantian kabel.

\section{3) Pengujian RTC}

Pada perancangan alat ini menggunakan RTC ditujukan untuk mengatur jadwal penyiraman tanaman pada pompa. Yang mana RTC akan mengirimkan perintah program penjadwalan waktu arduino untuk mengatur relay yang berfungsi untuk menghidupkan pompa air. Pompa disetting akan ON selama 5 detik pada pukul 07.00, 12.00, dan 16.00. pengujian dilakukan dengan cara membandingkan hasil dari RTC dengan waktu pada laptop yang mana diatur otomatis menggunakan sistem bukan pengaturan manual sehingga keakuratannya cukup terjamin. Berikut hasil perbandingan hasil dari modul RTC yang ditampilkan serial monitor arduino, waktu di laptop yang memiliki fitur update otomatis sesuai dengan waktu setempat.

\begin{tabular}{|c|c|}
\hline & Send \\
\hline Current Date / 'I'me: 18/8/2019 & $20: 36: 4$ \\
\hline Current Date / Time: 18/8/2019 & $20: 36: 4$ \\
\hline Current Date / Time: 18/8/2019 & $20: 36: 4$ \\
\hline Current Date / Time: 18/8/2019 & $20: 36: 5$ \\
\hline Current Date / Time: 18/8/2019 & $20: 36: 5$ \\
\hline Current Date / Time: 18/8/2019 & $20: 36: 5$ \\
\hline Current Date / Time: 18/8/2019 & $20: 36: 5$ \\
\hline Current Date / Time: 18/8/2019 & $20: 36: 5$ \\
\hline Current Date / Time: 18/8/2019 & $20: 36: 5$ \\
\hline Current Date / Time: 18/8/2019 & $20: 36: 5$ \\
\hline Current Date / Time: 18/8/2019 & $20: 36: 5$ \\
\hline Current Date / Time: 18/8/2019 & $20: 36: 5$ \\
\hline Current Date / Time: 18/8/2019 & $20: 36: 5$ \\
\hline Current Date / Time: 18/8/2019 & $20: 36: 5$ \\
\hline Current Date / Time: 18/8/2019 & $20: 36: 5$ \\
\hline Current Date / Time: 18/8/2019 & $20: 36: 5$ \\
\hline VAutoscroll & re ending -9600 baud $\rightarrow$ Clear output \\
\hline
\end{tabular}

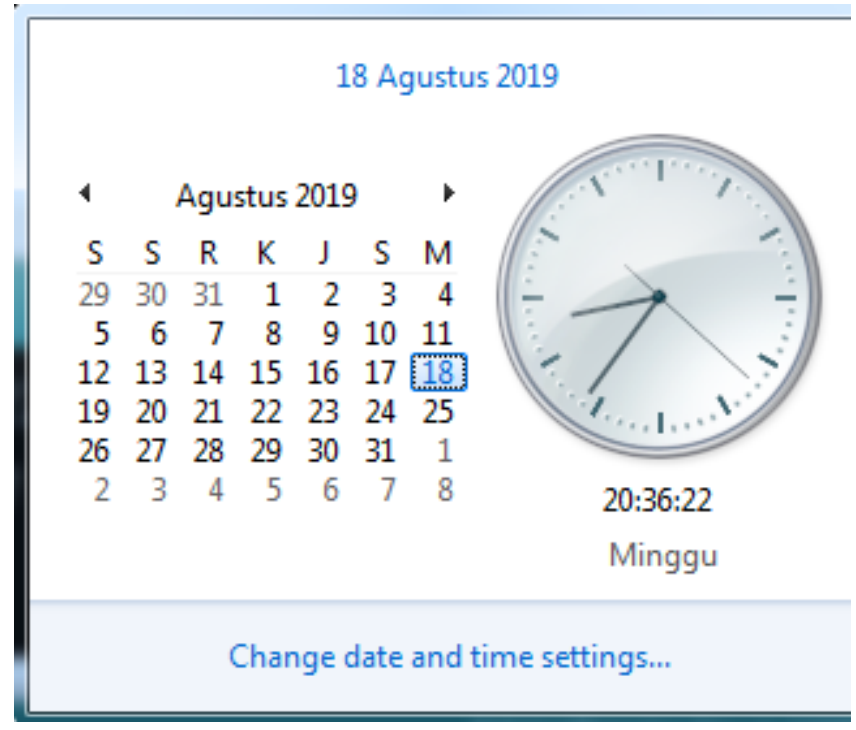

Gambar 4. Hasil Pengujian RTC

Dari hasil pengujian diatas dapat disimpulkan bahwa modul RTC yang digunakan keakuratannya teruji dengan baik, karena memiliki perbedaan hanya dalam perhitungan detik.

\section{4) Pengujian PIR}

Sistem akan bekerja mulai dari sensor PIR yang mendeteksi adanya gerak disekitar tanaman. Oleh karena itu sebelumnya kita harus memperhatikan apakah semua komponen sudah terhubung dengan sempurna atau belum. Karena jika ada satu komponen yang tidak terhubung dengan tepat maka sensor PIR tidak akan bisa mendeteksi adanya hama atau serangga yang mendekat pada tanaman. Jika sensor PIR mendeteksi adanya gerakan, maka kipas akan ON selama 2 detik. 


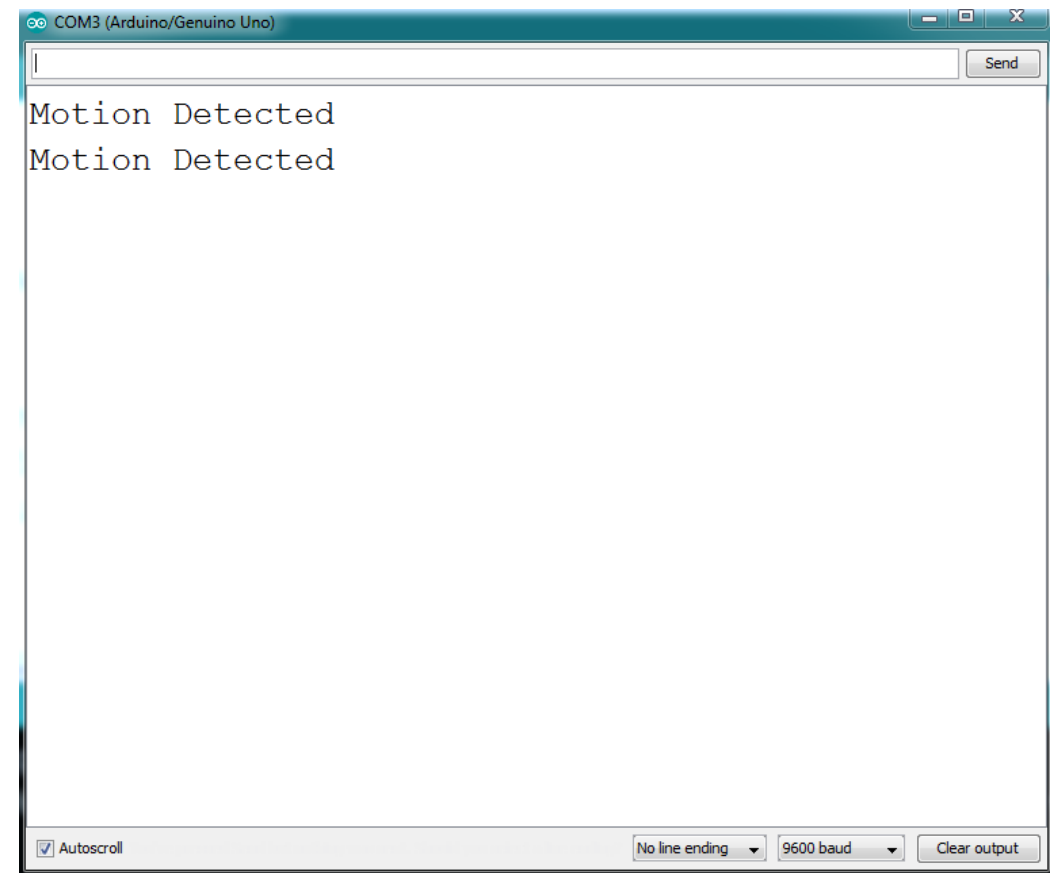

Gambar 5. Program telah berjalan

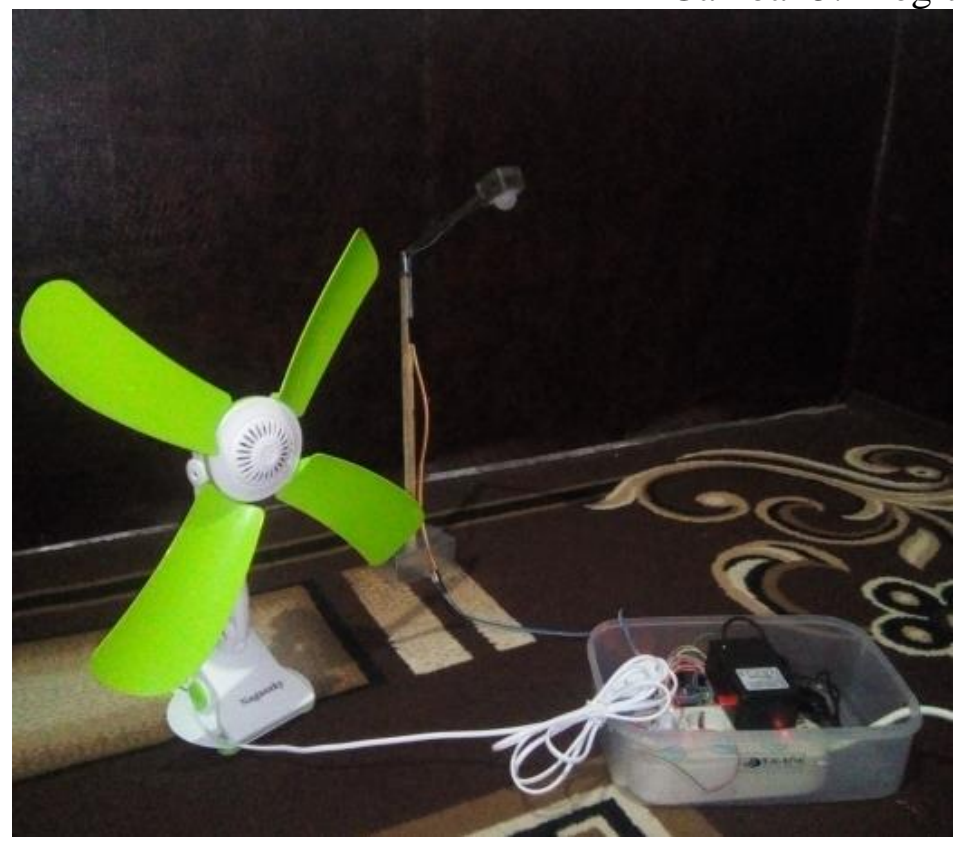

Sensor PIR tidak mendeteksi gerakan / Kipas OFF

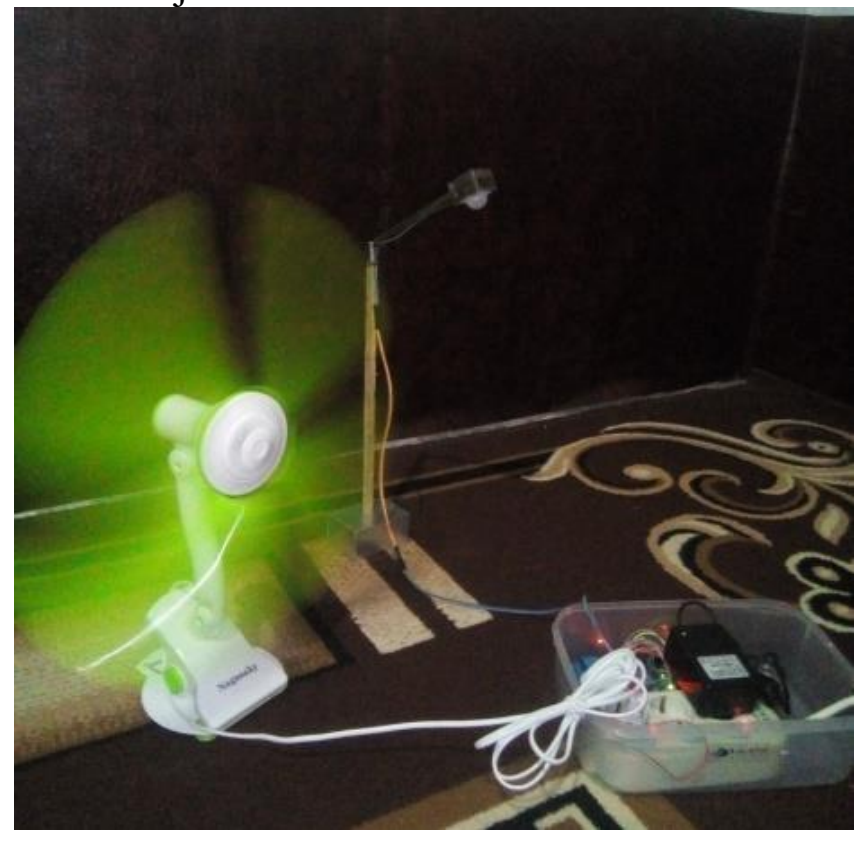

Sensor PIR mendeteksi adanya gerakan / Kipas ON

Gambar 6. Hasil kinerja Sensor PIR

\section{B. Pengujian Terhadap Objek}

Pengujian terhadap objek dilakukan selama setengah bulan. Dimulai pada pertengahna bulan Juli sampai dengan awal bulan Agustus 2019.Pengujian dilakukan dengan dua metode, yaitu dengan metode manual dan metode otomatis.menggunakan alat.

\section{1) Pengujian secara manual}

Selama masa pengujian penyiraman tanaman peppermint dilakukan secara manual, menggunakan tenaga manusia. Yaitu disiram dengan gayung dan jika ada hama atau serangga yang mengganggu tanaman peppermint tidak bisa mengusirnya. 


\section{2) Pengujian objek menggunakan alat}

Pengujian objek menggunakan alat dilakukan selama setengah bulan, menggunakan media tanaman peppermint yang sudah berumur 3 bulan.

a. Pengujian secara otomatis

Pengujian dengan alat terhadap tanaman peppermint dilakukan selama setengah bulan, pada pertengahan bulan juli s.d awal bulan Agustus 2019. Sedangkan penyiraman dan pengusir hama otomatis pada tanaman peppermint dilakukan secara otomatis dengan alat seperti pada gambar 6

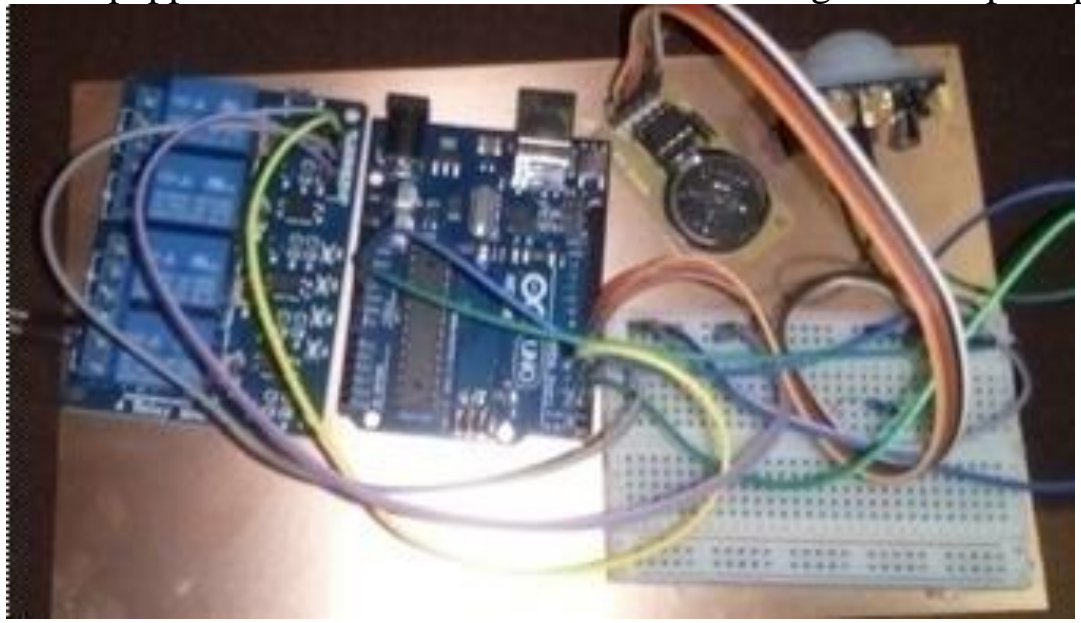

Gambar 7. Pengujian Arduino Uno RTC-PIR-Relay

Pada pengujian alat ini RTC disetting hanya akan menyala pada pukul 07.00/12.00/16.00 Wib. Jadi selain pada jam tersebut maka air tidak akan mengalir atau tidak akan menyiram tanaman. Dan sensor PIR disetting apabila ada sesuatu yang mendekat (jika ada gerakan) di sekitar tanaman, maka kipas akan menyala. Sehingga jika ada hama atau serangga yang mendekat akan segera pergi meninggalkan tanaman tersebut.

\section{3) Antisipasi pada saat pengujian}

a. RTC dan sensor PIR tidak akan berfungsi apabila terkena air, karena komponen ini sangat sensitif terhadap air. Hal ini diantisipasi dengan meletakkan semua komponen dalam satu wadah yang tertutup. Kecuali untuk sensor PIR, sensor PIR ini dibuatkan penutup sendiri karena sensor PIR harus diletakkan diluar agar bisa mendeteksi hama atau serangga yang mendekat dan mengganggu tanaman.

b. Mikrokontroler sebagai otak atau pengendali utama pada alat penyiram dan pengusir hama otomatis ini juga tidak bisa terkena air. Untuk mengantisipasi, penulis meletakkan mikrokontroler, relay dan RTC pada satu tempat yang tertutup. Dengan begitu komponen akan terlindungi dari air dan bisa bekerja secara maksimal.

\section{4) Validasi Produk}

Dalam validasi produk ini terdapat beberapa aspek, diantaranya yaitu :

1. Aspek kelayakan desain produk

a. Kesesuain desain dengan manfaat.

b. Kesesuaian desain dari segi keamanan.

c. Kesesuaian desain dari segi troubleshooting.

2.Aspek kelayakan interface

a. Kesesuaian produk dari segi peletakan.

b. Kesesuaian produk dari segi kemudahan pengguna.

c. Kesesuaian produk dari segi estetika.

3. Aspek kelayakan penyajian

a. Teknik penyajian 

b. Pendukung penyajian
c. Koherensi dan keruntutan alur piker
d. Pelibatan pengguna

4.Aspek akurasi modul
a. Akurasi modul / komponen
b. Koherensi antar modul
c. Unjuk kerja modul
d. Unjuk kerja sistem keseluruhan

5.Aspek kontektual

a. Hakikat kontekstual

b. Komponen kontekstual

Berdasarkan validasi yang telah dilakukan dengan beberapa aspek diatas dihasilkan respon yang baik oleh validator, yaitu mencapai $70 \%$. Sehingga alat otomatis ini dinyatakan bahwa layak untuk digunakan sebagai penghemat tenaga manusia.Ada satu catatan dari validator yaitu SOP atau petunjuk penggunaan alat otomatis ini yang masih belum tersedia.

\section{5) Uji coba produk (alat dan media)}

Pada uji coba produk terdapat beberapa aspek yaitu meliputi :

a. Aspek pengetahuan kemanfaatan alat

b. Aspek kelayakan interface

c. Aspek kemudahan pemakaian alat

d. Aspek efektifitas dan efisiensi alat

Berdasarkan uji coba produk (alat dan media) kepada beberapa user dari berbagai profesi didapatkan hasil sebagai berikut :

a. Rata - rata diantara mereka belum pernah mengetahui penggunaan alat kontrol otomatis ini sebelumnya.

b. Menurut pendapat user alat ini perlu digunakan untuk membantu meringankan tenaga mereka.

c. Pemakaian alat ini mudah karena dilengkapi dengan petunjuk penggunaan.

d. Penggunaan alat ini dirasa efektif oleh para user.

\section{KESIMPULAN}

Perancangan sistem penyiraman dan pengusir hama otomatis pada tanaman peppermint menggunakan mikrokontroler arduino uno sebagai pengolah data atau sebagai otak dari alat ini. Cara kerja alat ini adalah sensor RTC disetting dengan tiga waktu yaitu pagi, siang, dan sore. Sensor PIR disetting jika ada gerakan hama atau serangga yang mendekati daun akan memberikan reaksi pada kipas sehingga hama atau serangga tersebut akan segera pergi dan tidak akan mengganggu tanaman peppermint. Semua program tersebut diolah dalam program mikrokontroler arduino uno.

\section{SARAN}

Pengujian terhadap jenis tanaman mint berbeda - beda. Diperlukan pengujian lanjutan terhadap masing - masing jenis tanaman mint yang berbeda. Dikarenakan tanaman mint banyak sekali jenisnya. Penelitian selanjutnya penyiraman dan pengusir hama peppermint secara otomatis bisa ditambah sensor suhu untuk digunakan pada saat musim hujan. 


\section{DAFTAR PUSTAKA}

[1] Kadir, Djaelani Abdul. 2019. http://mplk.politanikoe.ac.id/index.php/program-studi/28-manajemenpertanian-lahan-kering/informasi-materi-kuliah-praktek1/164-belalang. Politeknik Pertanian Negeri Kupang Nusa Tenggara Timur (NTT). 07 Agustus 2019

[2] Ramdani. Penerapan Fuzzy Inference Sistem Untuk Kontrol Suhu Dan Kelembaban Budidaya Jamur Tiram Berbasis Mikrokontroler. Universitas Satya Negara Indonesia. Jurnal Ilmiah Fakultas Teknik LIMIT'S Vol. 12 No. 1

[3] Salman, Muhammad Ibnu Chaer. Aplikasi Mikrokontroler Arduino Pada Sistem Irigasi Tetes Untuk Tanaman Sawi (Brassica Juncea). Universitas Mataram. Jurnal Ilmiah Rekayasa Pertanian dan Biosistem, Vol.4, No. 2

[4] Sugiono. 2016. Cara Mudah Menyusun Skripsi, tesis, dan disertasi (STD).Universitas Bandung: ALFABETA.

[5] Syahid, Arif. Cara Menanam Daun Mint. https://ilmubudidaya.com/cara-menanam-daun-mint. 18 Maret 2019.

[6] Triyanto, Anggi. Pengatur Suhu dan Kelembapan Otomatis Pada Budidaya Jamur Tiram Menggunakan Mikrokontroler ATMega16. TESLA Vol. 18 No. 1

[7] Wahyu, Alfian Aji. Sistem Penyiraman Otomatis Vertical Garden Dengan Arduino Berbasis Web.Universitas Islam Indonesia Yogyakarta.

[8] Wiyanto, Ari. 2018. Rancang Bangun Alat Penyemprot Tanaman Anggrekberdasarkankondisi Suhu Dan Kelembaban Tanah. Fakultas Teknologi InformasiUniversitas Islam Balitar. Blitar

[9] Zeth, Kafiar Erricson. Rancang Bangun Penyiram Tanaman Berbasis Arduino Uno Menggunakan Sensor Kelembaban YL-39 Dan YL-69. Universitas Sam Ratulaingi Manado. Jurnal Teknik Elektro dan Komputer Vol.7 No.3 